\title{
Problems of Sustainable Development of Dairy Industry Enterprises in the Conditions of Western Sanctions and in the Framework of the Import Substitution Program
}

\author{
Iraida Romanova \\ Department of Agronomy and Ecology \\ Smolensk State Agricultural Academy \\ Smolensk, Russia \\ Ryulia1@yandex.ru
}

\author{
Yulia Romanova \\ Financial University under the Government of the Russian \\ Federation \\ Institute of Market Problems \\ Moscow, Russia \\ Ryulia1@yandex.ru
}

\begin{abstract}
The article is devoted to the topical issues of economic development and growth of the dairy industry enterprises. Analytical work was carried out to study the strategy of sustainable development of the food and processing industry of the Russian Federation. The approach to improving and modernizing the dairy industry is of particular interest. The main attention is drawn to the materials of the Ministry of Industry of the Russian Federation, which are focused on the importance of taking into account performance indicators, scientific publications, the citation of articles, employment in the education sector, etc. The task of developing food enterprises, in particular dairy industry, remains extremely relevant and insufficiently developed in the scientific literature.
\end{abstract}

Keywords-economic efficiency; food industry; dairy industry; modernization

\section{INTRODUCTION}

In modern conditions of import substitution, the food industry is one of the most important elements of food security and independence, as it is the given sector that provides the population with food products, forms a certain part of the GDP, participates in the formation of the country's international image.

In addition, at present it is necessary to develop methods for determining the indicators of the quality of dairy raw materials and finished dairy products. Unfortunately, there is almost no production of many food ingredients and substances in the country. Therefore, it is necessary to establish own production with the use of modern technologies and with the involvement of a scientific community, which needs financial support just like the production itself.

The questions and problems of sustainable development of dairy enterprises were studied by such Russian authors as Brylo I.V., Veselovsky M.Y., Gnezdova Y.V., Gusev V.V., Enina D.V., Zelenina T.A., Klimova M.L., Kulagina N.A.,
Paskova I.V., Trubitsyna E.V., Schepetova V.A., Yatmanova A.A.

In this regard, the issues of sustainable development of dairy enterprises in the context of Western sanctions and the program of import substitution are among the most important problems of the Russian food industry.

\section{TOPICAL ISSUES OF THE DAIRY INDUSTRY}

DEVELOPMENT IN THE CURRENT CONDITIONS OF THE FOOD INDUSTRY DEVELOPMENT

Five years have passed since April 17, 2012, when the decree of the Government of the Russian Federation approved an encouraging document for the industry called "Strategy for the development of the food and processing industry of the Russian Federation for the period until 2020" (hereinafter referred to as the Strategy), which was meant for solving industry problems in the food industry through achieving performance targets with the help of resource and financial provision. An interim assessment of the Strategy shows that the criteria for approaching the main goals of the food and processing industry require adjustment or even a fundamental revision. According to the Strategy, nowadays more than 1500 enterprises of different capacities carry out the production of dairy products in Russia. At the same time, only a small part of the enterprises is modernized and reconstructed, and mainly at the expense of the entrepreneurs themselves.

In the medium-term period (2013-2016) there is such a priority as the raw material base of livestock products, the development of which requires the use of the mechanisms set out in the subprogram "Development of the Livestock SubSector, Processing and Sale of Livestock Products" (hereinafter - the Subprogram) of the State Program of developing agriculture and regulating the markets for agricultural products, raw materials and food for 2013-2020 (hereinafter - the State Program). Despite the priority, the 
problem of reducing the production of dairy raw materials remains unsolved. Today there is a shortage of raw milk in the Russian market [1].

Another problem is the seasonal nature of milk production. Now we are speaking about the seasonal nature of the production of raw milk, and not about the seasonality of production of finished products, which is almost not seen in whole-milk production, but is noticeable in cheese making, butter making and drying production (milk powder). Therefore, it is important to eliminate the seasonal nature of the production of marketable milk [2]. This will largely predetermine the price of milk sales (the market itself will regulate it), the profitability of its production and, as a consequence, the financial stability of enterprises. And the industrial capacities of the industry will be provided with maximally balanced loading.

The reduction in the seasonality of dairy production is hindered to a greater extent by the lack of qualified specialists and management in dairy farming, as well as inadequate measures of state support. Farmers can reduce the aggravation of the seasonal nature of milk production themselves by ensuring regular control over the time of fertilization of the breeding stock and calving uniformity, strict adherence to the rules of conducting anti-epizootic measures (search and liquidation of sick animals) and other industrial measures [3].

The next serious problem is the low absolute weight of premium grade milk products. Butter-making enterprises and the drying industry suffer from the lack of milk of the highest grade. In this situation our industry will not be export-oriented for a long time and the products will not take a firm place in the exchange trades. Dairy farms lack refrigeration equipment. This problem is also reflected in Strategy 2020. In this respect, Russian-made equipment has a big advantage over foreign equipment which is its low cost. However, the quality of Russian equipment leaves much to be desired. Unfortunately, domestic engineering works in the distance from the real needs of the dairy industry and farms.

Thus, the issue of reconstructing and modernizing production is very acute, which, in fact, was reflected in Strategy 2020. Here it is appropriate to give the example of the Republic of Belarus, which long ago understood that processing industry is the locomotive of the dairy industry. Enterprises conducted a total modernization under a previously approved plan. In five years the country managed not only to fully provide itself with milk, but also to establish a strong channel for selling a significant share of its production to Russia [4].

It should be recognized that milk processing plants have physical and moral wear of fixed assets. However, no steps are taken to improve the situation and achieve one of the strategic objectives of the government document. Besides, the existing technical base does not provide comprehensive processing of milk: secondary dairy raw materials are not used everywhere to produce competitive products, it is often not returned to production and simply merges into sewage. Therefore, it is extremely important to expand the list of measures to support the Russian food industry, including granting financial vacations for modernization, especially with regard to the development of the best available technologies and everything related to it [5].

Another problem is the falsification of raw milk and dairy products, the emergence of which largely triggered the shortage of dairy raw materials, the tough financial situation of industrial enterprises, the lack of systematic supportive policies and the ever-changing situation in the milk market. This situation left no choice to enterprises and led to cost optimization, using cheap ingredients, inexpensive vegetable palm oil, a scheme to bypass controlling bodies and avoiding responsibility under imperfect legislation. Thus, all these tendencies led to falsification of raw materials and finished products. Unauthorized use of certain components of the product, as well as using medicinal veterinary drugs in agricultural production, is exacerbated by the absence of a single information system for traceability of the quality of food products in the chain of its production and circulation. Perhaps, the development and implementation of electronic veterinary certification by the Federal Veterinary And Phytosanitary Monitoring Service will solve this problem. At present, the process of combating falsification is delayed, and until now many issues in this respect have not been solved [6].

\section{THE STRATEGY FOR THE DEVELOPMENT OF THE DAIRY INDUSTRY UNDER THE CONDITIONS OF SANCTIONS AND THE PROGRAM OF IMPORT SUBSTITUTION}

It should be noted that the year 2016 was marked by a decline in consumer demand for dairy products. There are several reasons for this: the increase in the consumer price, a big amount of falsification, ignoring social projects for the population, adverse publicity of milk in the mass media, lack of public explanations and educational information in preschool and school institutions concerning the useful properties of various groups of dairy products. It was proven long ago that the culture of dairy products consumption is formed in a person from childhood. The main social project created for these purposes in Russia is the special program "School Milk", which should be considered as an effective mechanism for increasing production and expanding the sales market. The possibility of releasing intervention stocks in support of domestic producers could be the best investment in the processing industry through the social program "School Milk", raised by the state to the federal level of financing.

Whereas the State declares the concern for public health and aims to stimulate the consumption of quality dairy products by the "Strategy for improving the quality of food products," another document developed by the Ministry of Health of the Russian Federation says the opposite. The Ministry of Health of the Russian Federation proposed the project called "Strategies for the formation of a healthy lifestyle for the population, prevention and control of noncommunicable diseases for the period until 2025" (hereinafter - Healthy Lifestyle Strategy). If the document is adopted in the form in which it is proposed, the "Strategy for the Development of the Food and Processing Industries of 
the Russian Federation for the Period until 2020" will lose its relevance [7].

The first doubtful point in this document is the introduction of mandatory use of iodized salt in the entire food industry. Meanwhile, in the technology of dairy products production the use of iodized salt is impossible, since this negatively affects the organoleptic (taste and color) of dairy products (there are specific flavors and smells, bitterness, etc.). Moreover, iodine can negatively affect biochemical processes during fermentation, ripening, and other important technological operations of manufacturing dairy products. The use of iodized salt is not regulated in any standard as a raw material for dairy products, therefore it is necessary to eliminate the legislative fixation of the use of iodized salt in dairy products. Undoubtedly, it is necessary to support medical concerns in terms of preserving the health of the population with iodine deficiency in Russia, but, by no means due to the mandatory use of iodized salt in general dairy products.

Another important issue is a systematic and purposeful reduction in consuming dairy products of high fat content [8]. In our opinion, this can lead to a possible exclusion of butter and melted butter, high-fat and melted cheeses, curd cheeses and desserts, sour cream, cream, canned goods from whole milk and, as a result, will destroy all industrial production. Low-fat dairy products lose significantly to the classic fatty products in terms of flavor and aroma, since milk fat, like milk protein, is a carrier for flavoring compounds. Besides, production of traditional products with a high content of natural milk fat does not require the use of artificial food additives in order to improve and maintain their consistency, which means they are more "clean" and physiologically useful.

In addition, there is a category of the population, for example children, residents of the Far North, who simply need to consume milk fat as a source of nutrients and energy for growth and development of the body. All these points can lead to discrediting dairy products, reducing the production of classical and traditional products, driving them out of the market, increasing the share of falsified dairy products (vegetable fats) and, as a result, the total stagnation of the dairy industry in Russia [9].

"The strategy for the development of the food and processing industry of the Russian Federation for the period until 2020" deals with one of the most important issues of the dairy industry - the improvement of the ecological situation in the industrial zones of production. By 2020 milk processing enterprises should reduce the man-caused environmental burden, form an environmental control system, and introduce environmental management and technology with the use of modern energy-saving solutions and equipment. As early as in 2018 enterprises will be subject to fines for non-compliance with environmental legislation. It is generally accepted that the main environmental impact of milk processing plants is pollution of the environment by wastewater discharges. In connection with this the Federal Law No. 7-FZ of 10.01.2002 "On Environmental Protection" provides economic incentive measures (application of coefficients to the rates of payment for negative impact on the environment). Enterprises can achieve 0 fees "for causing harm to the environment" and avoid penalties using technologies to minimize waste emissions, using production and consumption waste in their own production in accordance with the technical regulations or transferring this waste for use within the period provided for by the legislation of the Russian Federation.

\section{CONCLUSION}

Today, analyzing the interim results, we should reflect on the following questions: "Why is the "Strategy for the development of the food and processing industry of the Russian Federation for the period until 2020" stalling?", "Why there are no new plants being built?", "Why are production capacities half loaded?", "Why are the prices per one liter of milk in production and on the consumer shelf significantly different?", and finally, "Why must producers invest their own funds in environmental protection and face all the problems of the state governmental scale without any help from the state?" No doubt there are a lot of issues to be solved. The state, business, and science should be involved more actively as the necessary conditions for the modernization of the industry have not been created yet. It is amazing how, being in a unique situation of sanctions, we waste time and do not increase our own production.

\section{REFERENCES}

[1] T. A. Zelenina, Dairy industry in the Altai Territory and prospects for development. Cheese and butter making, 2013, No. 5, pp. 24-29.

[2] E. V. Trubitsyna. Effective management of investment activities of the dairy industry on the basis of reservation. Bulletin of the NorthCaucasian Federal University, 2010, No. 4, pp. 265-269.

[3] A. A. Yatmanova, What will happen to the Russian dairy industry? New science: Experience, traditions, innovations. 2015. No. 7-1, p. 233

[4] V. Brylo, M. L. Klimova, Dairy industry of the Republic of Belarus, trends and development prospects. Dairy Industry, No. 2, 2017, pp. 10-14.

[5] V. A. Shchepetova, The milk industry as one of the sources of environmental pollution. Education and science in the modern world. Innovation, No. 3, 2016, pp. 66-69.

[6] Y. V. Gnezdova, M. Y. Veselovsky, Problems of investment safety management in the region - Economics of Russian agriculture, No. 9, 2016, pp. 7-14.

[7] V. Paskova, Dairy and the WTO. Collection: Russia and the WTO Economic, Legal and Social Aspects, The Fourth International Scientific Student Congress, 2013, pp. 2085-2090.

[8] N. A. Kulagina, Dairy industry in the system of assessing the economic security of the agro-industrial complex. Collection The Economics and Law in Russia and Abroad. Proceedings of the First All-Russia Scientific Practical Conference, Organizing Committee of the Publishing Group SVIWT, 2011, pp. 46-50.

[9] V. V. Gusev, The socio-economic aspects of improving competitiveness of the food industry enterprises (on the example of the dairy industry of the Saratov Region), Bulletin of Tomsk State University, Philosophy. Sociology. Political Science, No. 1, 2009, pp. $153-160$ 